\title{
INJECTION OF PROXIMAL INTERPHALANGEAL JOINT BY HAPTIC SUPPORTED VIRTUAL REALITY ENVIRONMENTS
}

\author{
Turhan Civelek, Kirklareli University, turhancivelek@klu.edu.tr \\ Hakan Kissaboylu, Kirklareli University, hakan.kissaboylu@klu.edu.tr \\ Dilek Cokar, Istanbul Bilim University, dilekkissaboylu@hotmail.com \\ Hakan Ustunel, Istanbul Science and Art Center, hakanustunel@hotmail.com
}

\begin{abstract}
In Medicine, Joint injections are the leading procedures of frequent usage. Effects of Haptic supported virtual reality environments on joint injections which give serious pain to patient, if haven't been done absolutely right, was aimed to analyze in this research. These environments allow the user to try the developed application for infinite time. In this paper, a haptic supported virtual reality environment was designed for the physicians. An algorithm was developed for this environment, and coded with $C++$ based Quick-Haptics programming language. A $3 D$ hand model which is created from computed tomography images and a $3 D$ syringe were used in the developed application. The developed virtual reality application was used with Geomagic ${ }^{T M}$ haptic device and head mounted Display by randomly selected medical students who answered a questionnaire consisting 27 questions after the trial of the application. Questionnaire result was analyzed with machine learning by using J48 algorithm in WEKA software. Analyses showed that Haptic supported virtual reality environments give more motivation and influences students with the opportunity of human computer interaction.
\end{abstract}

Keywords: Haptic Devices; OpenHaptics; Virtual Reality Environments; Injection; Software Development; Human Computer Interaction

\section{INTRODUCTION}

Haptic perception means to touch (Salisbury J. , 1999). In this paper, the usage of the word "haptic" can be defined as; interaction of a person with a virtual object by way of touch (Avila, 1996). Haptic devices which contain virtual objects have been studied for many years. The first usage of haptic devices was tele remotes which were used to carry hazardous chemical and nuclear stuffs in 1940s. Due to the progress of Phantom ${ }^{\mathrm{TM}}$ haptic device in early 1990s, haptic interaction usage for information technologies grew significantly (Salisbury \& Srinivasan, 1997) .

Haptic devices return some types of feedbacks. These feedbacks are categorized as Force and Tactile. Force Feedback reproduces weight, motion interdiction of objects, while Tactile Feedback enables users to feel the roughness, edges and warmness of the objects (Burdea, 2000). Tactile Feedback sensory was used for the approaches of haptic object recognition and localization (Aggarwal \& Kirchner, 2014). There are more examples of feedback studies like positioning joy-sticks (Rubio-Sierra \& Stark, 2003), sensation of tactile soft matters (Heller, 2002), surgical training platforms ( Zhang, et al., 2012), medical inspection in haptic supported virtual reality environment(HSVRE) ( $\mathrm{Li}$, et al., 2015), and multimodal neuro-surgery applications ( Kuroda, Kamada, Hayashi, Imura, \& Oshiro, 2011).

The usage of HSVRE, are widely growing in our everyday lives with respect to the synchronous expansions in software and hardware of computer sciences. There is a remarkable acceleration in process of entertainment and education in HSVRE, due to developing 3-D images and animations, head mounted displays (HMD) and haptic devices for human-computer interaction ( KAYABAŞI, 2005). 
Ordinary class implementations that are taught all around the Globe is linked on learning with optic senses, such as course-books, written formulas and graphics (Jones, et al., 2014). HSVRE systems play a more fertile part on (Civelek, 2015) abstract notions than ordinary education manners (Bozkurt, 2008).

Haptic device usage in several education systems is rapidly increasing. The importance of HSVRE is the chance of repetitive trial that is given to the user (Civelek, Ucar, \& Gokcol, 2014). HSVRE usage for medical, nursing and dental students' practices occupies an important place. A Previous research shows that with additional haptic education, nursing students learned quicker than the individuals that were just educated with practical exercises for venipuncture injection (Jung, et al., 2012) .There are also studies on haptic supported injection implementations, such as polymethylmethacrylate (PMMA) injection into cancellous bone (Lian, Chui, \& Teoh, 2008), Micro-robotic cell injection ( Ghanbari, Horan, Nahavandi, Chen, \& Wang, 2014), epidural injection simulator (Dang, Annaswamy, \& Srinivasan, 2001), Biological-Cell Injection ( Ammi \& Ferreira, 2005), intravenous injection simulator (Tsai, Fung, Tsai, Jeng, \& Doong, 2008).

Joint injection is a drug application which is applied to joint space or periarticular tissue. The aims of application are treatment and relieve symptoms of directly joint or joint components (Dinçer, 2013). In medicine, Syringe is used to inject anti-inflammatory medicines or to extract synovial fluid to aid diagnosis for proximal interphalangeal joint diseases, such as, trigger fingers, rheumatoid arthritis, osteoarthritis and systemic lupus erythematosus (Shinomiya, et al., 2015). In this paper, an education method of haptic supported virtual injection system was aimed to develop.

\section{Implementation of HSVRE \& Haptic Device Fields}

In near future, virtual reality for 3-D visualization and haptic supported machines will fill a wide space in human life. HSVRE study is a promising area. The best point of HSVRE technology is its adaptable features to every field like geography, entertainment, science, medicine, learning systems, architecture, and engineering.

First of all, haptic technologies are used in medical students' education applications, such as surgical operations, neuro-surgery (Lemore, Banerjee, Luciano, Neckrysh, \& Charbel, 2007), co-worked surgeoncies' (Qin, Choi, Poon, \& Heng, 2009), force-feedback imaging of cardiac surgery virtual platforms (Nakao, et al., 2002), risky cardiovascular involvements (Mayer, et al., 2007) tactile platforms of vertebral insertion ( Luciano, et al., 2013). HSVRE technologies are also used for technical improvement of the haptic devices (Çavuşoğlu, Feygin, \& Tendick, 2002) and machine-based experiments of physics, mathematics and the other parts of scientific studies ( Yan, Hou, Zhang, Kang, \& Zheng, 2009). Also some social aimed needs could be area of these kinds of investigations ( Kaklanis, Votis, \& Tzovaras, 2013).

\section{RESEARCH METHODOLOGY}

Effects of HSVRE usage on education of joint injection was aimed to observe. During this research a 3D hand model was created in $3 \mathrm{Dslicer}^{\mathrm{TM}}$ application which provides users to change computed tomography (CT) images to 3D objects. This hand model was set in a virtual reality environment and a haptic supported simulation was designed. 35 randomly selected medical students were chosen to apply the designed simulation. Moreover, these students were asked to answer a questionnaire consists of 27 questions with the answers of 'Low', 'Medium', 'Good' and 'Very good' except the $27^{\text {th }}$ question which had two answers as 'Yes' or 'No'.

WEKA is a widely known, open source machine learning software. Graphical and visual opportunities make WEKA a favorable option for machine learning. It's necessary to have opinions about results of researches. There are some methods for that aim. Accuracy rate, precision, recall and F-measure are one of them (Aydogan, Gencer, \& Akbulut, 2008).

Precision and recall are not enough to get exact results. F-measure, which is harmonic average of precision (P) and recall (R), is defined to solve this problem (Han \& Kamber, 2006). F-measure value has better learnt the relationship between algorithm classes that are close to 1. F-measure is calculated as follows: 
F-measure $(F)=\frac{2 * P^{*} R}{(P+R)}$

Kappa value (K) describes the reliability of comparison between observers ( (Cohen, 1960), (Fleiss, 1971) ). The purposeful interval of Kappa-value is between -1 and $1 . \mathrm{K}$ is 1 when there is an exact concurrence comparison between observers. Negative values of kappa $(\mathrm{K}<0)$ are meaningless in terms of reliability. The range of 0.41 and 1.0 is acceptable value for $\mathrm{K}$ (Landis \& Koch , 1977). If $\mathrm{P}_{\mathrm{o}}$ is acceptable rate and $\mathrm{Pc}$ is the expected rate, $\mathrm{K}$ is calculated as follows:

Kappa value $(K)=\frac{\left(P_{o}-P_{c}\right)}{\left(1-P_{c}\right)}$

\section{Procedure}

Common indications for joint injections include insertion of therapeutic agents like steroids, lidocaine, and hyaluronic acid to relieve inflammation, pain and to increase function of joint (Sallis). Indications of joint injections are inflammatory conditions such as rheumatoid arthritis and osteoarthritis. Please refer table1 to see common indications for joint injections (Dinçer, 2013).

Table 1. Common Indication for Joint Injections

\begin{tabular}{|c|}
\hline \\
\hline İnflammatory Arthritis \\
\hline Rheumatoid Arthritis And Juvenil Rheumatoid Arthritis \\
\hline Crystal İnduced Arthropaties ( Gout, Pseudogout) \\
\hline Noninflammatory Arthritis \\
\hline Osteoarthritis ( Knee, Hip, Shoulder, Hand Joints) \\
\hline Periarticular Soft Tissue İnjections \\
\hline Bursitis \\
\hline Entrapment Neuropathies (Especially Carpal Tunnel Syndrome) \\
\hline Epicondylitis \\
\hline Tenosynovitis \\
\hline
\end{tabular}

This procedure can be applied to knee, hip, shoulder or hand joints. In this research, Proximal Interphalangeal (PIF) joint injections are focused on. In PIF injection finger should be in semiflexion position so joint space could widen, progress should be on perpendicular axis from medial or lateral of extansor tendon on dorsal face of hand. To progress the joint may be painful and hard to apply. $1.5 \mathrm{~cm}$ injector and $0.25-0.5 \mathrm{cc}$ corticosteroid can be used in injection procedure (Dinçer, 2013). (Figure1) 


\section{Issues in Information Systems \\ Volume 17, Issue III, pp. 89-99, 2016}
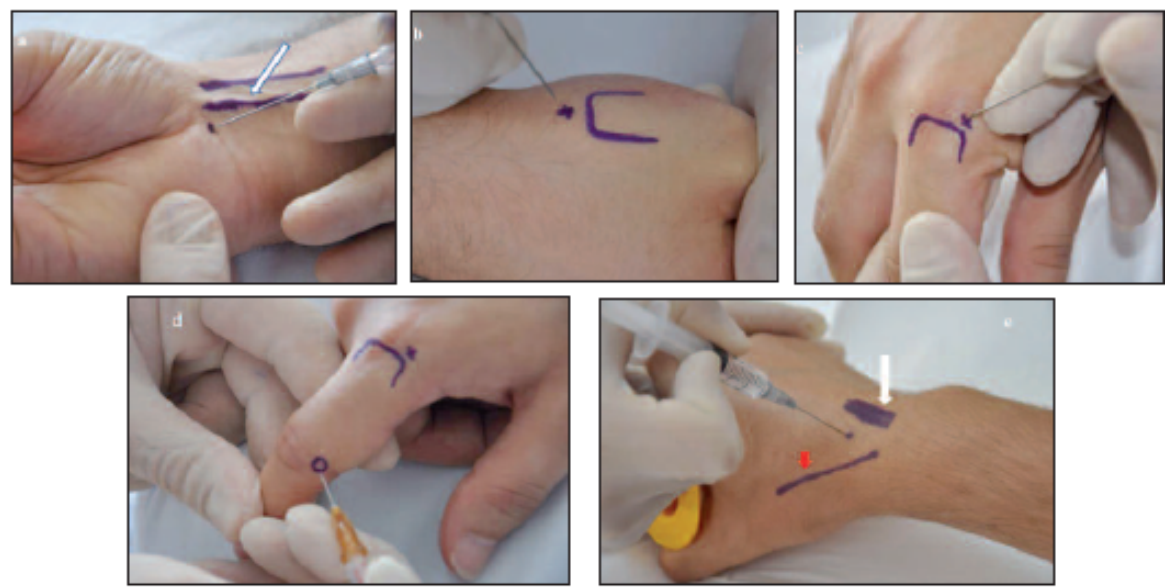

Figure 1. Hand joints injections: (a) Carpal Tunnel Syndrome (b) 1. Metacarpophalangeal joint (c) Metacarpophalangeal joint (d) proximal interphalangeal joint e) Radiocarpal Joint

\section{D Modeling}

A 3D hand model was designed in an appropriate file format for the software development environment before the coding process of injection application. The model was aimed to design as in real world. Therefore, CT images were inserted in 3DSlicer ${ }^{\mathrm{TM}}$ environment and almost the same hand model created with the format of STL which is suitable for the coding language. Afterwards, for the adjustment and localization of this created hand model, Rhino ${ }^{\mathrm{TM}}$ environment was used.

\section{Software Development}

One of the significant steps for HSVRE is application coding. An improvement on education of injection usage of medicine students is aimed with the developed application. Knowledge of absolute injection point is crucially important. There are rules that must be followed before and during the injection (Sallis). HSVRE application that provide education must be developed proper to these rules. An algorithm was developed to explore a solution for the problem of critical proximal interphalangeal joint injection. (Figure2)
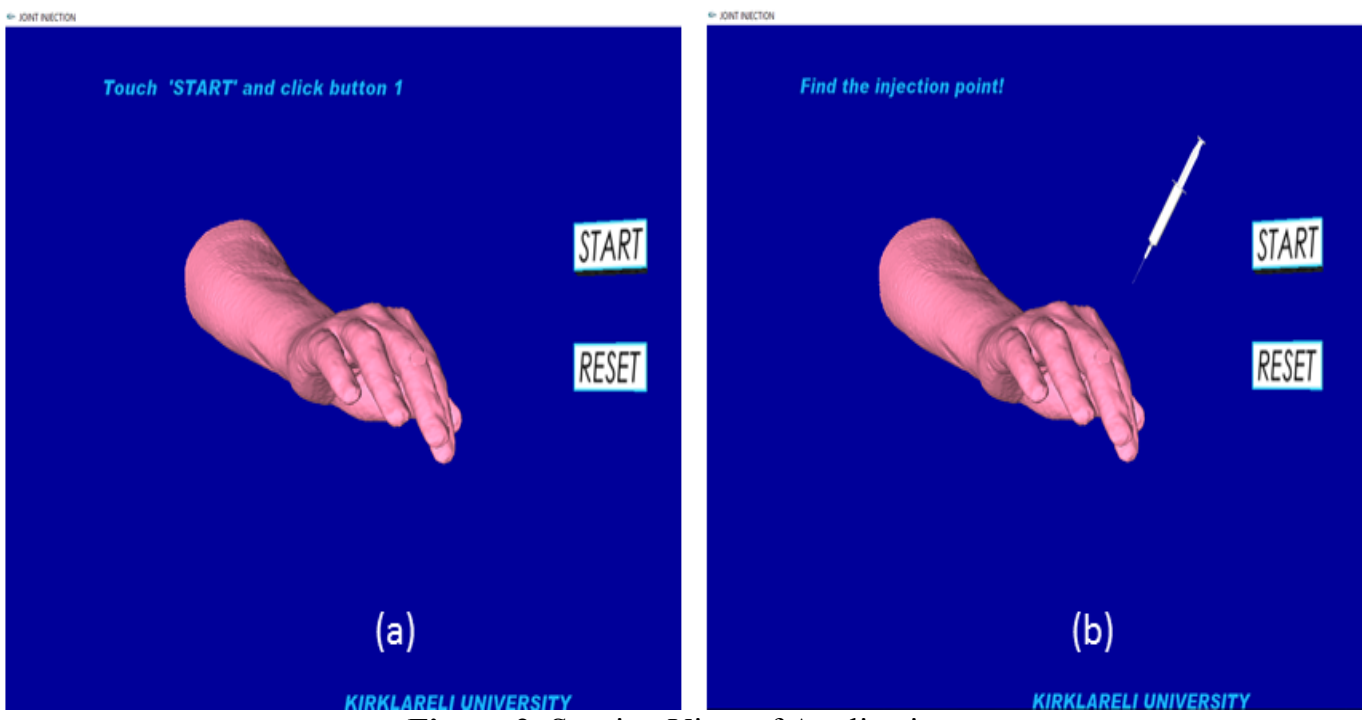

Figure 2. Starting View of Application 
HSVRE of joint injection was coded on visual studio environment with $\mathrm{C}++$ and Quick-Haptics. Algorithms of buttoncallback, touchcallback, force and tactile feedbacks were coded. In this application, a syringe attached to haptic device. While the user is trying to insert to not the desired injection point, a force applied to device and user cannot insert inside the model. On the other hand, when the user finds the injection point, application warns him/her and if the injection is being done with the aimed angle, algorithm lets the user for the injection and syringe inserts through the model. (Figure 2) System gives success message and haptic device doesn't put on resistance during injection to this point. Arm does its process easily.

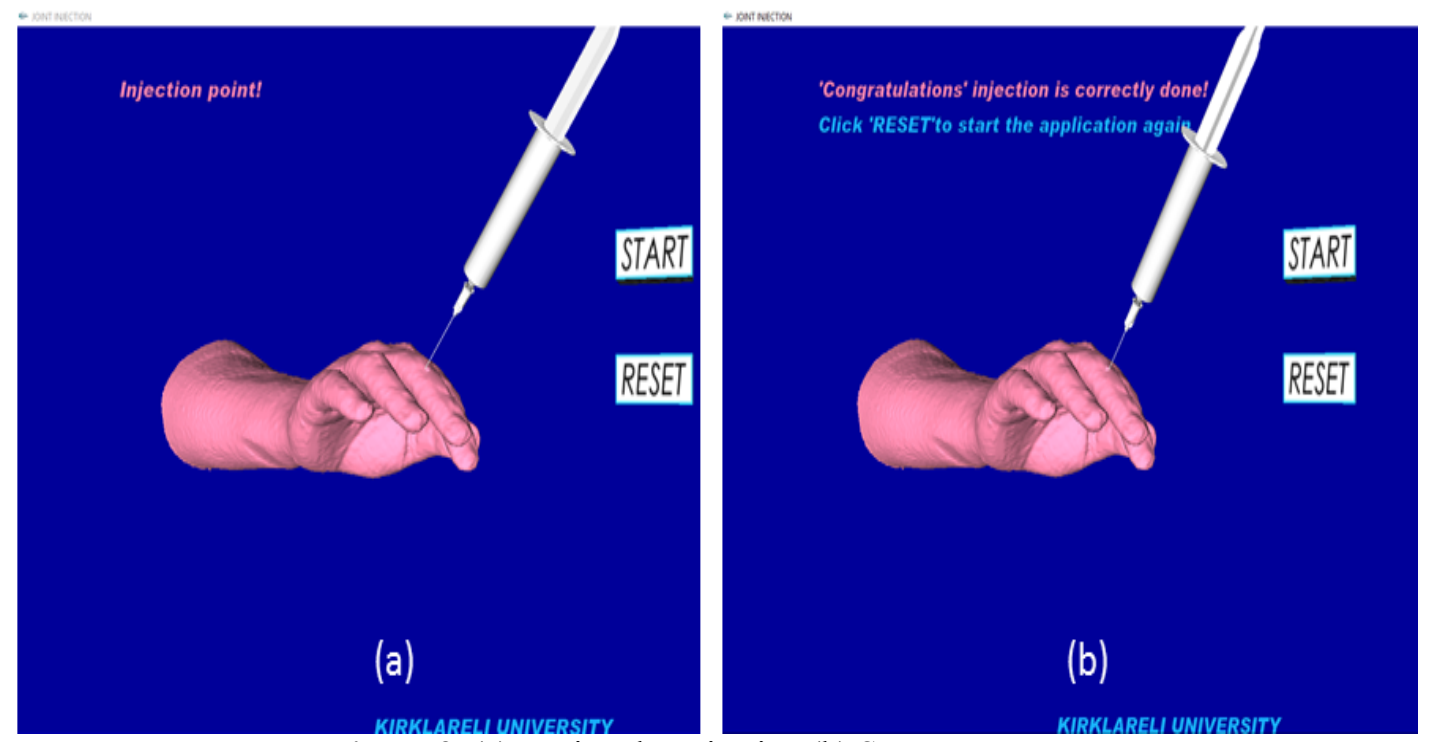

Figure 3. (a) During the Injection (b) Success Message

In order to continue the application, reset button can be used for new trials. Repetitive trials of haptic education are thought to make the learning of the joint injection more obvious. (Figure 3)

\section{Algorithm of the Application}

A cursor is created and attached with haptic device after the creation of display window. Objects are added to the environment. Coordinates and features of the objects are defined for the workspace. During the simulation position of cursor and object are always compared. After the interaction of object and cursor, functions work as a loop to give returns to the user. (Figure 4)

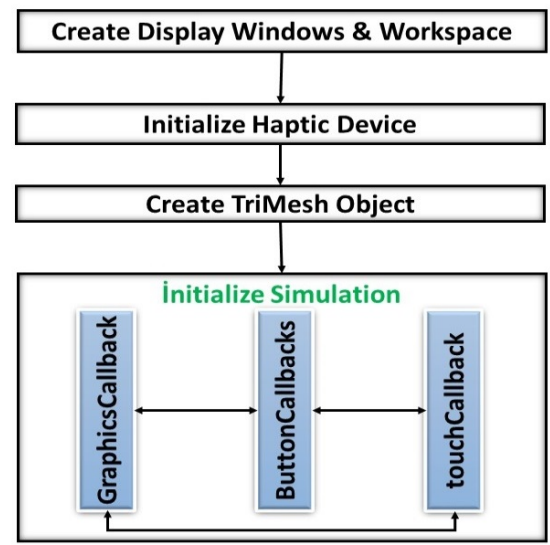

Figure 4. Algorithm of the Developed Software 


\section{Implementation of Learning Environment}

Application, 3-D display units, haptic device and computer interaction and HSVRE was developed. For visualization of virtual reality environment head mounted display and Geomagic ${ }^{\mathrm{TM}}$ were used.

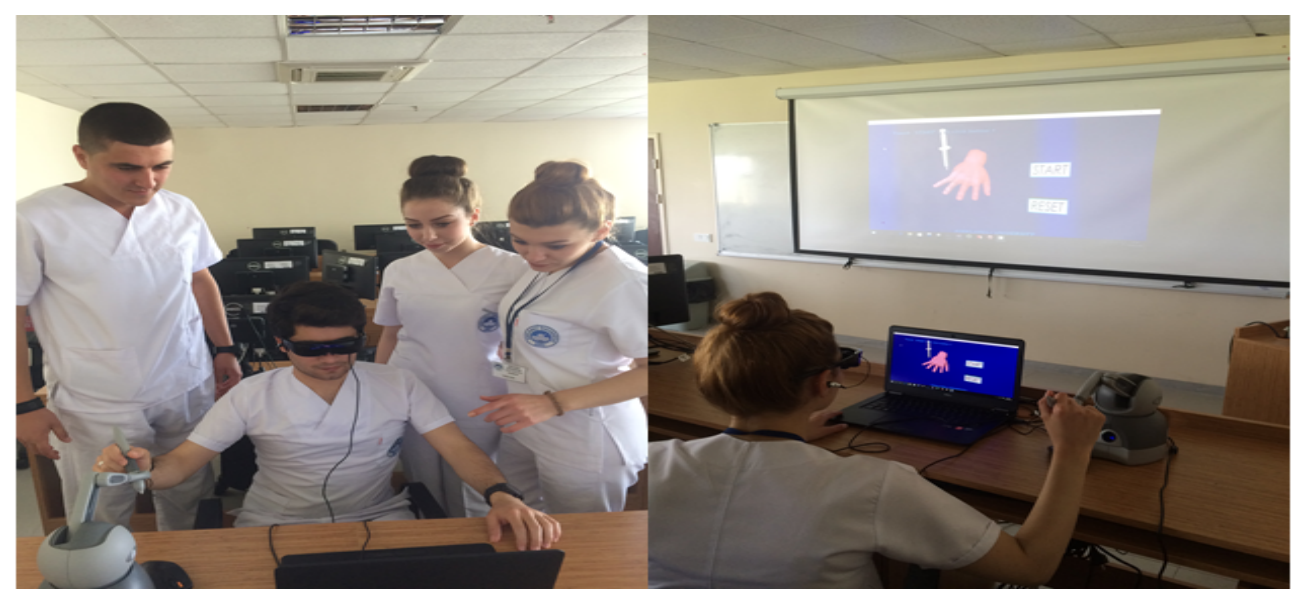

Figure 5. Medical Students Trying the Application

Head mounted display (HMD) which gives 3-D visualization was mounted to the participants' head and developed application activated during process (refer to Figure 3). Haptic device's touch arm is used by hand to control syringe on the screen. Inserting of Syringe isn't allowed to any part of hand, except the desired and marked joint region. Haptic arm put up resistance and doesn't insert in other parts of hand. Therefore, user was stimulated by a given force feedback. A difficulty occurs on arms motion, during syringe's rub to other parts of the hand.

35 students from faculty of health in Kirklareli University tried the simulation and were asked to answer a questionnaire with 27 questions about haptic devices, HSVRE's, realization of the simulation. According to the questionnaire some analyses were done to observe the efficiency of the application and haptic devices in medical education.(Figure 5)

\section{RESULTS}

For every question, true classification scores of J48 are better than scores of primitive algorithm ZeroR. This shows that J48 achieve successful learning algorithm. Kappa's statistic value shows that J48 algorithm accomplishes acceptable and successful learning between 0.41 to 0.60 and 0.61 to 1.00 .

Table 2. ZeroR Algorithm

\begin{tabular}{|c|c|c|c|c|c|c|c|c|}
\hline Question & $\begin{array}{c}\text { Kappa } \\
\text { Statistic }\end{array}$ & $\begin{array}{c}\text { Correctly } \\
\text { Classified } \\
\text { Instances }\end{array}$ & $\begin{array}{c}\text { TP } \\
\text { Rate }\end{array}$ & $\begin{array}{c}\text { FP } \\
\text { Rate }\end{array}$ & Precision & Recall & $\begin{array}{c}\text { F- } \\
\text { Measure }\end{array}$ & $\begin{array}{c}\text { ROC } \\
\text { Area }\end{array}$ \\
\hline 14 & 0 & $48.57(17)$ & 0.49 & 0.49 & 0.24 & 0.49 & 0.32 & 0.35 \\
\hline 15 & 0 & $57.14(20)$ & 0.57 & 0.57 & 0.33 & 0.57 & 0.42 & 0.40 \\
\hline 17 & 0 & $45.71(16)$ & 0.46 & 0.46 & 0.21 & 0.46 & 0.29 & 0.34 \\
\hline 18 & 0 & $48.57(17)$ & 0.49 & 0.49 & 0.24 & 0.49 & 0.32 & 0.36 \\
\hline 21 & -0.08 & $37.14(13)$ & 0.37 & 0.46 & 0.26 & 0.37 & 0.28 & 0.34 \\
\hline 22 & 0 & $45.71(16)$ & 0.46 & 0.46 & 0.21 & 0.46 & 0.29 & 0.33 \\
\hline 24 & 0 & $40.00(14)$ & 0.40 & 0.40 & 0.16 & 0.40 & 0.23 & 0.37 \\
\hline 25 & 0 & $42.85(15)$ & 0.43 & 0.43 & 0.18 & 0.43 & 0.26 & 0.34 \\
\hline
\end{tabular}


In WEKA, for the questions of $14,15,17,18,21,22,24,25$ separated classifications were made with ZeroR primitive algorithm, and 35 samples were classified respectively as 17 ones $48.57 \%$, 20 ones $57.14 \%, 16$ ones $45.71 \%, 17$ ones $48.57 \%, 13$ ones $37.14 \%, 16$ ones $45.71 \%, 14$ ones $40.00 \%, 15$ ones $42.85 \%$ of them accurately as seen in Table 1.

Table 3. J48 Algorithm

\begin{tabular}{|c|c|c|c|c|c|c|c|c|}
\hline Question & $\begin{array}{c}\text { Kappa } \\
\text { Statistic }\end{array}$ & $\begin{array}{c}\text { Correctly } \\
\text { Classified } \\
\text { Instances }\end{array}$ & $\begin{array}{c}\text { TP } \\
\text { Rate }\end{array}$ & $\begin{array}{c}\text { FP } \\
\text { Rate }\end{array}$ & Precision & Recall & $\begin{array}{c}\text { F- } \\
\text { Measure }\end{array}$ & $\begin{array}{c}\text { ROC } \\
\text { Area }\end{array}$ \\
\hline 14 & 0.67 & $80.00(28)$ & 0.80 & 0.12 & 0.78 & 0.80 & 0.80 & 0.79 \\
\hline 15 & 0.59 & $77.14(27)$ & 0.77 & 0.13 & 0.75 & 0.77 & 0.76 & 0.88 \\
\hline 17 & 0.52 & $71.42(25)$ & 0.71 & 0.15 & 0.73 & 0.71 & 0.72 & 0.86 \\
\hline 18 & 0.63 & $77.14(27)$ & 0.77 & 0.14 & 0.75 & 0.77 & 0.76 & 0.81 \\
\hline 21 & 0.68 & $80.00(28)$ & 0.80 & 0.10 & 0.80 & 0.80 & 0.79 & 0.85 \\
\hline 22 & 0.54 & $71.43(25)$ & 0.71 & 0.14 & 0.67 & 0.71 & 0.68 & 0.71 \\
\hline 24 & 0.56 & $71.43(25)$ & 0.71 & 0.13 & 0.70 & 0.71 & 0.70 & 0.81 \\
\hline 25 & 0.57 & $71.43(25)$ & 0.71 & 0.12 & 0.72 & 0.71 & 0.72 & 0.81 \\
\hline
\end{tabular}

In WEKA, for the questions of $14,15,17,18,21,22,24,25$ separated classifications were made with J48 algorithm, and 35 samples were classified respectively as 28 ones $80.00 \%, 27$ ones $77.14 \%, 25$ ones $71.42 \%, 27$ ones $77.14 \%, 28$ ones $80.00 \%, 25$ ones $71.43 \%, 25$ ones $71.43 \%, 25$ ones $71.43 \%$ of them accurately as seen in Table 1.

When two tables are compared, it's obvious that F-measures of J48 algorithm are greater than the ones of ZeroR. FMeasure value of J48 algorithm is closer to 1 . These results of WEKA analyze shows that $\mathrm{j} 48$ accomplished a better machine learning.

Learning was accomplished in the following questions with $\mathrm{j} 48$ algorithm;

Q2. Does HSVRE motivate you?

Q7. Do you think using HSVRE with haptic devices in lecturing provides you more efficient learning?

Q11. Does HSVRE courage you to make researches?

Q14. Does using HSVRE for applications make easy integration with lessons for students?

Q15. Can HSVRE make lessons more attractive?

Q17. Does HSVRE help you to connect the new information with your old knowledge?

Q18. Does HSVRE give opportunity to see materials which cannot be taken into classrooms?

Q21. Do designed VR environments provide you to objectify subjects?

Q22. Do you think working with haptic devices in VR environments can increase your success in medical

education?

Q24. Does HSVRE provide suitable settings for injection applications?

Q25. Does the designed environment provide you to understand concepts like joint injection?

Q26. Can HSVRE be used for the preparation of injections?

Q27. Does the Medical Education supported with HSVRE present a better opportunity than the traditional medical education?

J48 algorithm classified the data set. It divided data by choosing the best root value. Decision tree structure was built for the each correctly learnt question from top to bottom.

Best root values placed to the top of the tree. Other root values placed through down according to the gain condition. Therefore, graphical representation of the decision trees created with high accuracy as seen in the figures below. Decision tree structure was built by choosing the best root value. Placement of roots according to the sorting of questions that succeed acceptable learning are given in the following figures as decision tree structures. 
Table 4. Decision Trees for Questions of 14, 15, 17 and 18

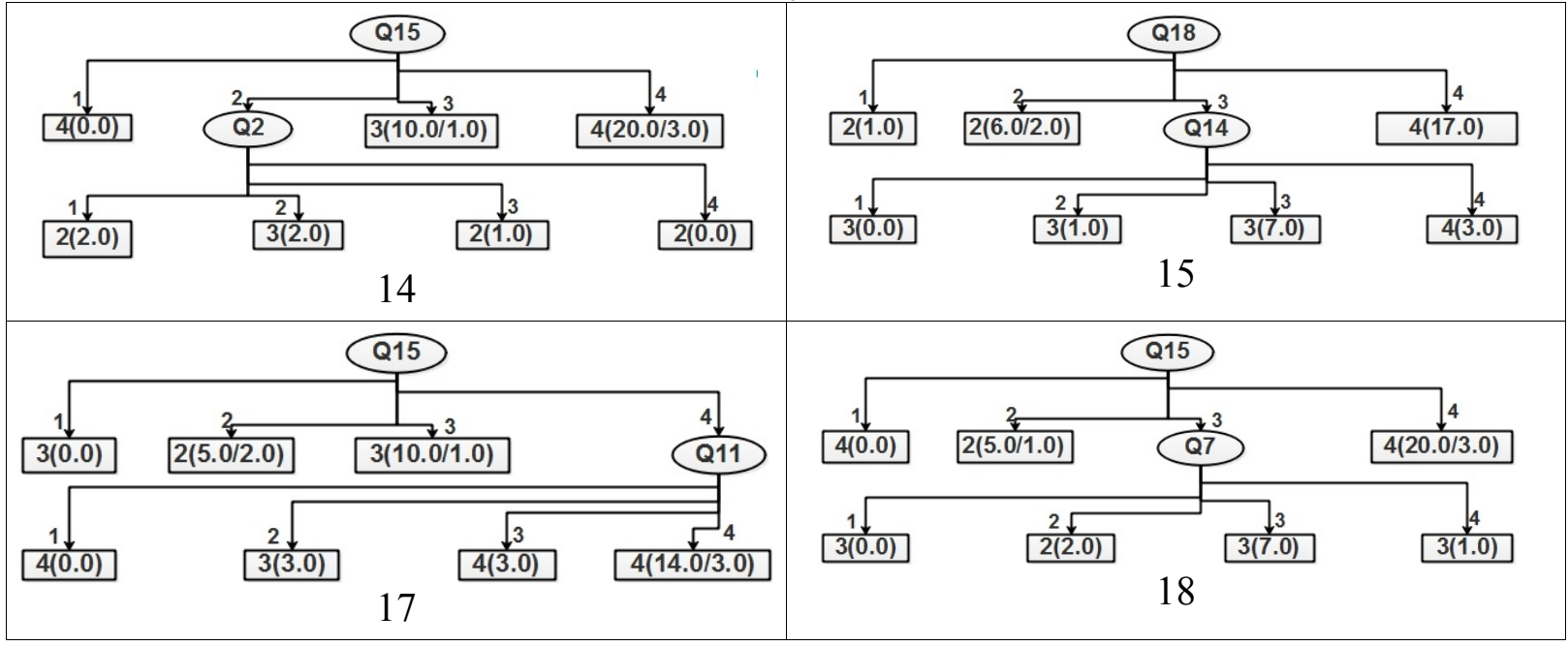

When the $14^{\text {th }}, 15^{\text {th }}, 17^{\text {th }}$ and $18^{\text {th }}$ questions are separately based on, respectively best root values are $15^{\text {th }}, 18^{\text {th }}, 15^{\text {th }}$ and $15^{\text {th }}$ questions for the accomplished learning with J48 algorithm. It has been learnt by the j48 algorithm that 26 student for $14^{\text {th }}$ question, 27 student for $15^{\text {th }}$ question, 23 student for $17^{\text {th }}$ question and 25 student for $18^{\text {th }}$ question answered "good" or "very good" from the students who answered the questions which are best root values $(15,18$, $15,15)$ as "good" and "very good".

Table 5 Decision Trees for Questions of 21, 22, 24 and 25

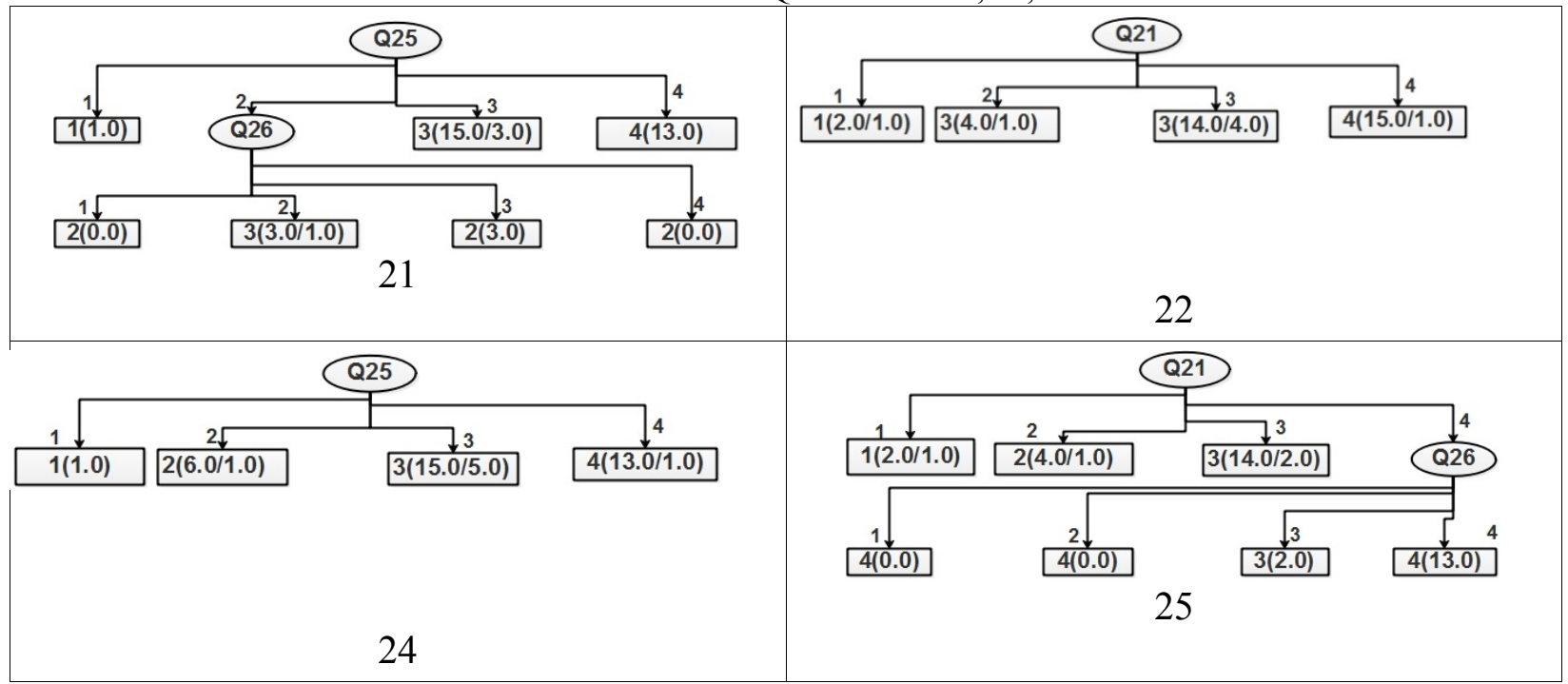

When the $21^{\text {st }}, 22^{\text {nd }}, 24^{\text {th and }} 25^{\text {th }}$ questions are separately based on, respectively best root values are $25^{\text {th }}, 21^{\text {st }}, 25^{\text {th }}$ and $21^{\text {st }}$ questions for the accomplished learning with J48 algorithm. It has been learnt by the j48 algorithm that 25 student for $21^{\text {st }}$ question, 24 student for $22^{\text {nd }}$ question, 22 student for $24^{\text {th }}$ question and 27 student for $25^{\text {th }}$ question answered "good" or "very good" from the students who answered the questions which are best root values $(25,21,25,21)$ as "good" and "very good".

All students who joined to research and answered the questionnaire answered the $27^{\text {th }}$ question as 'Yes'. 


\section{SUMMARY}

Proximal interphalangeal joint injection is a sensitive method which gives a considerable pain to patient, if it isn't done with the proper rules. In this paper, an educational HSVRE algorithm was designed for Medicine students' usage of virtual injection that gives force feedback. If the injection is applied to the desired point by obeying the rules, system allows inserting to the point and success message is given. On the other hand, if the user doesn't obey the rules, system gives force feedback and injection cannot be completed. Haptic supported joint injection provides a very effective chance for medical education due to its repetitive trial advantage.

From the results of machine learning provided by J48 algorithm of WEKA, Medical students who think HSVRE;

1. makes the course more interesting also thinks;

- it effects the integration to lesson (\%74.29), connects the new information with old knowledge (\%65.71) gives opportunity to see materials which cannot be taken into classrooms (71.43),

2. gives opportunity to see materials which cannot be taken into classrooms also thinks it makes the course more interesting $(\% 77.14)$,

3. provides individual to understand concepts of joint injection better also thinks;

- It provides user to objectify subjects in his/her mind(\%71.48) and suitable settings for injection applications (\%62.86),

4. provides user to objectify subjects also think;

- It can increase their success in medical education (68.57and provides individual to understand concepts of joint injection better ( $\% 77.14)$

This research shows that HSVRE make easy integration with lessons for students, connects the new information with old knowledge, makes the course more interesting and enlarges the number of materials used in the course. Results also show, it helps students to understand concepts of joint injection better, objectifies subjects in their mind, provides suitable settings for injection applications and can increase their success in medical education. Furthermore, all the students who attended to questionnaire think that education with HSVRE presents a better opportunity than the traditional medical education.

Results of this paper match up with the previous studies ( (Jung, et al., 2012), ( Ghanbari, Horan, Nahavandi, Chen, \& Wang, 2014), (Lian, Chui, \& Teoh, 2008), (Dang, Annaswamy, \& Srinivasan, 2001)) of HSVRE injection. In the future works, injection of other joints of human body and new HSVRE educational applications are recommended to investigate.

\section{REFERENCES}

Aggarwal, A., \& Kirchner, F. (2014, February). Object Recognition and Localization: The Role of Tactile Sensors. Sensors, 14(2), 3227-3266.

Ammi, M., \& Ferreira, A. (2005). Realistic Visual and Haptic Rendering for Biological-Cell Injection. International Conference on Robotics and Automation (s. 918-923). Barcelona: IEEE.

Avila, R. (1996). A Haptic Interaction Method for Volume Visualization. Proceedings of the 7th IEEE Visualization Conference (VIS'96) (s. 197-ff). Los Alamitos: IEEE.

Aydogan, E. K., Gencer, C., \& Akbulut, S. (2008). Churn Analysis AndCustomer SegmentationOf A CosmeticsBrand Using Data MiningTechniques. Journal of Engineering and Natural Sciences, 26(1), 4256.

Bozkurt, E. (2008). Fizik eğitiminde hazırlanan bir sanal laboratuar uygulamasının öğrenci başarısına etkisi. Turkey/Konya: Selçuk University. 
Burdea, G. (2000). Haptics Issues in Virtual Environments. Computer Graphics International, 2000. Proceedings (s. 295 - 302). Geneva: IEEE.

Civelek, T. (2015). The Haptic Aplication in Environment of Virtual Reality for Learning. Journal of Engineering and Architecture, 3(2), 1-9.

Civelek, T., Ucar, E., \& Gokcol, O. (2014). Effects of a Haptic Augmented Simulation on K-12 Students' Achievement and their Attitudes towards Physics. Eurasia Journal of Mathematics, Science \& Technology Education, 10(6), 565-574.

Cohen, J. (1960). A Coefficient of Agreement For Nominal Scales. Educational and Psychological Measurement, 20, 37-46. doi:10.1177/001316446002000104

Çavuşoğlu, M., Feygin, D., \& Tendick, F. (2002). A Critical Study of the Mechanical and Electrical Properties of the PHANToM Hapt ic Interface and Improvements for High Performance Control. Presence, 11(6), 555568.

Dang, T., Annaswamy, T., \& Srinivasan, M. ( 2001). Development and Evaluation of Epidural Injection Simulator with Force Feedback for Medical Training. Medicine Meets Virtual Reality, 81, 97-102.

Dinçer, Ü. (2013). Periferik Eklem Enjeksiyonları. Turkiye Klinikleri J PM\&R-Special Topics 2013;, 6(3), 22-30.

Fleiss, J. L. (1971). Measuring nominal scale agreement among many raters. Psychological Bulletin, 76(5), 378-382. doi: $10.1037 / \mathrm{h} 0031619$

Ghanbari, A., Horan, B., Nahavandi, S., Chen, X., \& Wang, W. (2014, June). Haptic Microrobotic Cell Injection System. IEEE Systems Journal, 8(2), 371-382.

Han, J., \& Kamber, M. (2006). Data Mining Concepts and Techniques. Francisco, CA: Morgan Kaufmann, Elsiver inc.

Heller, M. (2002). Tactile picture perception in sighted and blind people. Behavioural Brain Research, 135, 65-68.

Jones, M., Childers, G., Emig, B., Chevrier, J., Tan, H., Stevens, V., \& List, J. (2014). The Efficacy of Haptic Simulations to Teach Students with Visual Impairments About Temperature and Pressure. Journal of Visual Impairment \& Blindness, 108, 55-61.

Jung, E.-Y., Park, D., Lee, Y., Jo, H., Lim, Y. S., \& Park, R. W. (2012). Evaluation of practical exercises using an intravenous simulator incorporating virtual reality and haptics device technologies. Nurse Education Today, $32,458-463$.

Kaklanis, N., Votis, K., \& Tzovaras, D. (2013). Open Touch/Sound Maps: A system to convey street data through haptic and auditory feedback. Computers \&Geosciences, 57, 59-67.

KAYABAŞI, Y. (2005, July). SANAL GERÇEKLIK VE EĞITIMM AMAÇLI KULLANILMASI. The Turkish Online Journal of Educational Technology, 4(3), 151-158.

Kuroda, Y., Kamada, K., Hayashi, Y., Imura, M., \& Oshiro, O. (2011). Multimodal Neurosurgery Force Feedback System Based on Mesh Fusion Modeling. Biocybernetics And Biomedical Engineering, 31(2), 33-50.

Landis, J. R., \& Koch, G. G. (1977). The measurement of observer agreement for categorical data. PubMed, 33(1), 159-74. doi: $10.2307 / 2529310$

Lemore, G., Banerjee, P., Luciano, C., Neckrysh, S., \& Charbel, T. (2007, July). Virtual reality in neurosurgical education: part-task ventriculostomy simulation with dynamic visual and haptic feedback. Neurosurgery, 61(1), 142-149. 
Li, M., Konstantinova, J., Secco, E., Jiang, A., Liu, H., Nanayakkara, T., .. W Wurdemann, H. (2015). Using visual cues to enhance haptic feedback for palpation on virtual model of soft tissue. Med Biol Eng Comput, 53, $1177-1186$.

Lian, Z., Chui, C.-K., \& Teoh, S.-H. (2008). A biomechanical model for real-time simulation of PMMA injection with haptics. Computers in Biology and Medicine, 38, 304 - 312.

Luciano, C., Banerjee, P., Sorenson, J., Foley, K., Ansari, S., Rizzi, S., . . Roitberg, B. (2013, January). Percutaneous Spinal Fixation Simulation With Virtual Reality and Haptics. Neurosurgery, 72, 89-96.

Mayer, H., Nagy, I., Knoll, A., Braun, E. U., Bauernschmitt, R., \& Lange, R. (2007). Haptic Feedback in a Telepresence System for Endoscopic Heart Surgery. Presence, 16(5), 459-470.

Nakao, M., Oyama, H., Komori, M., Matsuda, T., Sakaguchi, G., Komeda, M., \& Takahashi, T. (2002). Haptic reproduction and interactive visualization of a beating heart for cardiovascular surgery simulation. International Journal of Medical Informatics, 68, 255-163.

Qin, J., Choi, K.-S., Poon, W.-S., \& Heng, P.-A. (2009). A framework using cluster-based hybrid network architecture for collaborative virtual surgery. computer methods and programs in biomedicine, 96, 205216.

Rubio-Sierra, F., \& Stark, R. (2003, April). Force-feedback joystick as a low-cost haptic interface for an atomicforce microscopy nanomanipulator. Applied Physics A, 76(6), 903-906.

Salisbury, J. (1999, August). Making graphics physically tangible. Communications of the ACM, 42(8), 74-81.

Salisbury, J., \& Srinivasan, M. (1997, May). Phantom-based haptic interaction with virtual objects. Computer Graphics and Applications, IEEE, 17(5), 6-10.

Sallis, R. (n.d.). Joint Injection and Aspiration. Fontana, US/California: American Academy of Family Physicians. Retrieved 02 20, 2016, from www.kau.edu.sa: http://www.kau.edu.sa/Files/140/Files/32394_16478_JointInjection.pdf

Shinomiya, R., Sunagawa, T., Nakashima, Y., Kawanishi, Y., Masuda, T., \& Ochi, M. (2015). Comparative study on the effectiveness of corticosteroid injections between trigger fingers with and without proximal interphalangeal joint flexion contracture. The Journal of Hand Surgery(European Volume), 41(2), 198-203.

Tsai, W.-W., Fung, C.-P., Tsai, S.-L., Jeng, M.-C., \& Doong, J.-L. (2008). The Assessment of Stability and Reliability of a Virtual Reality-Based Intravenous Injection Simulator. Computers, Informatics, Nursing, 26(4), 221-226.

Yan, F.-x., Hou, Z.-x., Zhang, D.-h., Kang, W.-k., \& Zheng, J.-q. (2009). Research of Haptic Techniques for Computer-Based Education. 4th International Conference on Computer Science \& Education (s. 1636 1640). Nanning: IEEE.

Zhang, L., Grosdemouge, C., Arikatlab, V., Ahnb, W., Sankaranarayananb, G., De, S., . . Cao, C. (2012). The added value of virtual reality technology and force feedback for surgical training simulators. IOS Press, 4l(1), 2288-2292. 